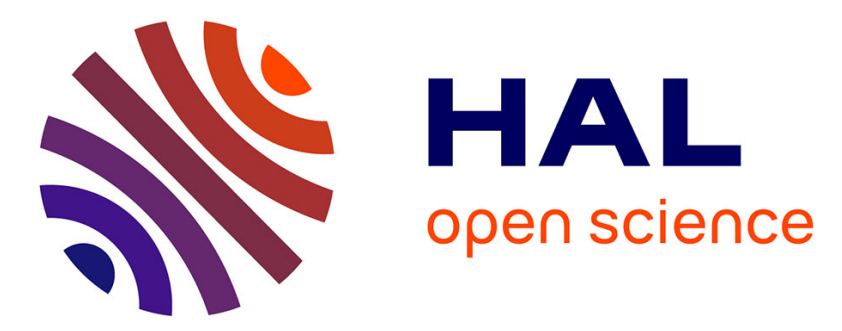

\title{
Synthesis of Functionalized Cyclobutenes and Spirocycles via Asymmetric P(III)/P(V) Redox Catalysis
}

Charlotte Lorton, Antoine Roblin, Pascal Retailleau, Arnaud Voituriez

\section{To cite this version:}

Charlotte Lorton, Antoine Roblin, Pascal Retailleau, Arnaud Voituriez. Synthesis of Functionalized Cyclobutenes and Spirocycles via Asymmetric P(III)/P(V) Redox Catalysis. Advanced Synthesis and Catalysis, 2021, 363 (20), pp.4805-4810. 10.1002/adsc.202100664 . hal-03402721

\section{HAL Id: hal-03402721 \\ https://hal.science/hal-03402721}

Submitted on 25 Oct 2021

HAL is a multi-disciplinary open access archive for the deposit and dissemination of scientific research documents, whether they are published or not. The documents may come from teaching and research institutions in France or abroad, or from public or private research centers.
L'archive ouverte pluridisciplinaire HAL, est destinée au dépôt et à la diffusion de documents scientifiques de niveau recherche, publiés ou non, émanant des établissements d'enseignement et de recherche français ou étrangers, des laboratoires publics ou privés. 


\title{
Synthesis of Functionalized Cyclobutenes and Spirocycles via Asymmetric P(III)/P(V) Redox Catalysis
}

\author{
Charlotte Lorton, ${ }^{\mathrm{a}}$ Antoine Roblin, ${ }^{\mathrm{a}}$ Pascal Retailleau ${ }^{\mathrm{a}}$ and Arnaud Voituriez*a \\ aUniversité Paris-Saclay, CNRS, Institut de Chimie des Substances Naturelles, UPR 2301, 91198, Gif-sur-Yvette, France. \\ E-mail: arnaud.voituriez@cnrs.fr
}

\begin{abstract}
An enantioselective phosphine-catalyzed transformation has been developed for the synthesis of chiral cyclobutene triesters and fluorinated spirocyclic compounds. The strategy involved a $\mathrm{P}(\mathrm{III}) / \mathrm{P}(\mathrm{V})$ redox cycling process, via in situ reduction of phosphine oxide with phenylsilane. This catalytic methodology has enabled the enantioselective synthesis of functionalized cyclobutenes ( 24 examples, up to

$94 \%$ ee). On the occasion of the extension of this study to $\alpha$-ketoester indenone substrates, a surprising reactivity has been discovered for the synthesis of spiroindenone products.

Keywords: Organocatalysis; Phosphine; Chirality; Cyclobutenes; Spiro compounds
\end{abstract}

Cyclobutanes and cyclobutenes are important structural units found in many natural products and pharmaceutical active compounds. ${ }^{[1]}$ Some representative natural cyclobutenes such as cyclomegistine or $\beta$-lumicolchicine are depicted in Scheme 1a. Due to the highly rigid backbone and the well-defined three-dimensional rearrangement of the substituents, these scaffolds are privileged in medicinal chemistry. ${ }^{[1 \mathrm{f}]}$ They can also be considered as key building blocks for the synthesis of highly substituted cyclic, heterocyclic or acyclic derivatives, via ring expansion, ring contraction or rearrangements. ${ }^{[2]}$ The asymmetric synthesis of substituted four-membered rings remains very challenging and a hot topic in organic synthesis, notably due to the difficulty to build highly-strained ring system in an efficient and stereoselective way.

Though the development of catalytic methodologies for the synthesis of chiral cyclobutanes is well documented, ${ }^{[3]}$ enantioselective syntheses of chiral cyclobutenes are relatively scarce (Scheme 1b). Various metal-catalyzed [2+2] cycloaddition reactions were developed between olefins and alkynyl sulfides, ${ }^{[4 a-b]}$ ynamides, ${ }^{[4 c-e]}$ electron-poor ${ }^{[4 f-h]}$ or electron-rich $^{[4 i-j]}$ alkynes. Other strategies for the synthesis of cyclobutenes include a copper-catalyzed 1,4-addition/trapping reaction of cyclobutenones ${ }^{[5]}$ and an intermolecular Heck annulation with propargylic acetates. ${ }^{[5 \mathrm{~b}]}$ Besides these metal-catalyzed methodologies, some enantioselective organocatalyzed processes appeared recently. Bach described an impressive enantioselective [2+2] photocycloaddition of dialkyl acetylenedicarboxylate with 2-pyridones, ${ }^{[6 a]}$ while Zheng reported a chiral phosphoric acid-catalyzed enantioselective desymmetrization reaction allowing the formation of chiral 3-aminocyclobut-2-en-1-ones. ${ }^{[6]}$ a. Representative cyclobutene-containing natural products ${ }^{[1]}$

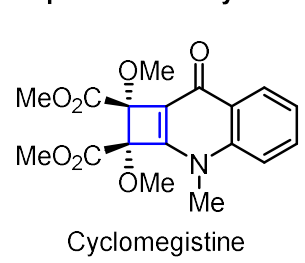<smiles>C=CC1C=C(OC)C(=O)C2=C1c1c(cc(OC)c(OC)c1OC)CCC2N</smiles>

$\beta$-Lumicolchicine

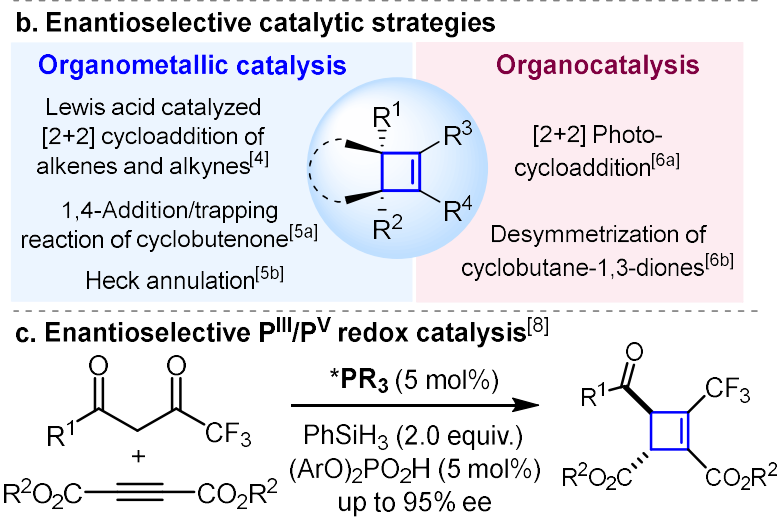

d. Extension of the methodology (this work)

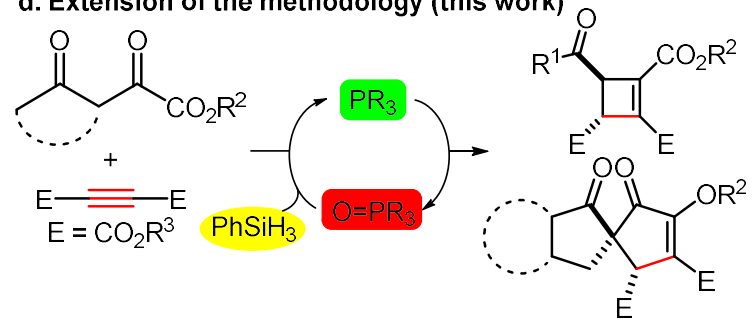

Scheme 1. (a) Representative natural products containing cyclobutenes, (b) and (c) known catalytic and asymmetric methodologies and (d) proposed work.

This sole couple of organocatalyzed examples led us to imagine and develop a new organocatalytic methodology. The proposed Michael addition/intramolecular Wittig reaction already proved its robustness, with the use of stoichiometric amounts 
of phosphine. ${ }^{[7]}$ Aiming at developing the first enantioselective phosphine-catalyzed formation of substituted cyclobutenes and exploring an underdeveloped disconnection strategy, we established in 2019 a catalytic and asymmetric $\mathrm{P}^{\mathrm{III}} / \mathrm{P}^{\mathrm{V}}$ redox cycling process (Scheme 1c) ${ }^{[8]}$ In order to develop catalytic and asymmetric transformations, phosphine oxide formed during the reaction was in situ reduced in the presence of phenylsilane. This strategy has been efficiently illustrated in many transformations over the past decade. ${ }^{[9]}$ Herein, we propose to fully explore the scope of enantioselective phosphine-catalyzed catalytic Michael addition/intramolecular Wittig reactions between dialkyl acetylenedicarboxylates (DAAD) and different 2,4-dioxo-4-arylbutanoates or fluorinated 2,3dihydro-1 $H$-inden-1-ones (Scheme 1d). Interestingly, the use of $\alpha$-ketoester indenone substrates allowed us to discover a new reactivity and the formation of unknown spirocyclic compounds. ${ }^{[10]}$

After developing the enantioselective synthesis of (trifluoromethyl)cyclobutenes in excellent yields and enantioselectivities ${ }^{[8]}$ we propose in the framework of this study to first expand the reactivity to 2,4-dioxo-4arylbutanoate substrates (Scheme 2). Reaction conditions were optimized by using ethyl 2-hydroxy4-oxo-4-phenylbut-2-enoate 1a and diethyl acetylenedicarboxylate $\mathbf{2}$ as model substrates. The initial catalytic system employs $10 \mathrm{~mol} \%$ of chiral phosphine, phenylsilane (2.0 equivalents) as reducing agent and a catalytic amount of bis(4nitrophenyl)phosphate, at $40{ }^{\circ} \mathrm{C}$ in toluene. Chiral HypPhos phosphines ${ }^{[11]}$ were first tested to find the right balance between reactivity and enantioselectivity. Screening of nine $P$-stereogenic phosphines, substituted with endo (I-IV) or exo (V-IX) aromatic ring possessing different electronic and steric properties gave the desired cyclobutene product 3a in up to $75 \%$ yield and $85 \%$ ee with phosphine IX.

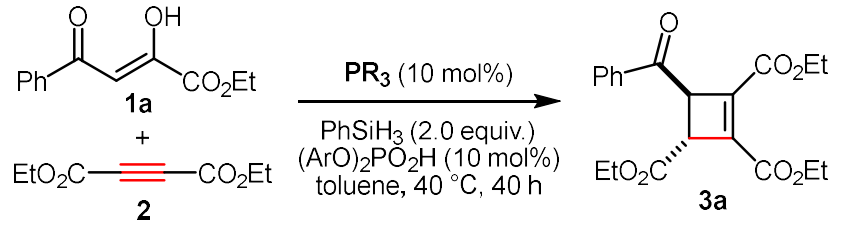

$$
\begin{aligned}
& \mathrm{PR}_{3}=1 \\
& \begin{array}{l}
\text { (I) } \mathrm{Ar}=\mathrm{Ph} ;<10 \% \text { yield } \\
\text { (II) } \mathrm{Ar}=\mathrm{pMeO}-\mathrm{C}_{6} \mathrm{H}_{4} ; 19 \% \text { yield, } 0 \% \text { ee } \\
\text { (III) } \mathrm{Ar}=2 \text {-naphthyl; } 70 \% \text { yield, } 59 \% \text { ee } \\
\text { (IV) } \mathrm{Ar}=1 \text {-naphthyl; } 40 \% \text { yield, } 73 \% \text { ee }
\end{array} \\
& \begin{array}{l}
\text { (V) } \mathrm{Ar}=\mathrm{Ph} ; 75 \% \text { yield, } 69 \% \text { ee } \\
\text { (VI) } \mathrm{Ar}=p \mathrm{~F}-\mathrm{C}_{6} \mathrm{H}_{4} ; 66 \% \text { yield, } 70 \% \text { ee } \\
\text { (VII) } \mathrm{Ar}=p M e-\mathrm{C}_{6} \mathrm{H}_{4} ; 35 \% \text { yield, } 83 \% \text { ee } \\
\text { (VIII) } \mathrm{Ar}=2 \text {-naphthyl; } 77 \% \text { yield, } 71 \% \text { ee }
\end{array} \\
& \text { (IX) } \mathrm{Ar}=1 \text {-naphthyl; } 75 \% \text { yield, } 85 \% \text { ee }
\end{aligned}
$$

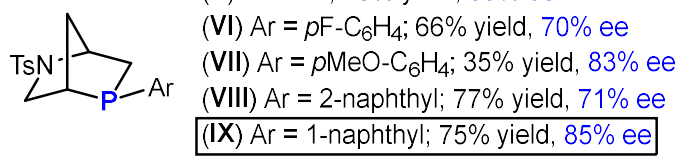

Scheme 2. Optimization of the catalytic and asymmetric tandem reaction.

In the development of $\mathrm{P}^{\mathrm{III}} / \mathrm{P}^{\mathrm{V}}$ redox processes, our group and others have repeatedly demonstrated the benefit of adding Brønsted acid in the reaction mixture. ${ }^{[9,12]}$ Here again, the presence of phosphoric acid proved to be essential, since it greatly facilitated the reduction of phosphine oxide. The best enantioselectivity was obtained with toluene as solvent at $40{ }^{\circ} \mathrm{C}$. A higher temperature $\left(60-80{ }^{\circ} \mathrm{C}\right)$ allows a faster reaction, but to the detriment of the enantiometric excess. Conversely, the reaction is slower at room temperature.

These optimal reaction conditions were then applied to the enantioselective formation of diversely substituted cyclobutenes (Scheme 3). The presence of electron-donating substituents such as methyl or benzyloxy groups, in different positions on the aromatic ring has low effect on both yields and enantiomeric excesses (compounds 3a-g, up to $98 \%$ yield, $81-89 \%$ ee). Absolute configuration of products was tentatively assigned to be $(3 R, 4 R)-\mathbf{3}$, by analogy with our previous work. ${ }^{[8]}$ When the substituent on the aromatic ring was replaced by an electronwithdrawing group, such as chloride, bromide or trifluromethyl, in ortho-, meta- or para-position, overall results remained very good (compounds $\mathbf{3 h}-\mathbf{n}$, $50-90 \%$ yield, $86-94 \%$ ee). Substrates substituted with heteroaryls such as furan and thiophene also furnished efficiently the corresponding products 3o-3p.

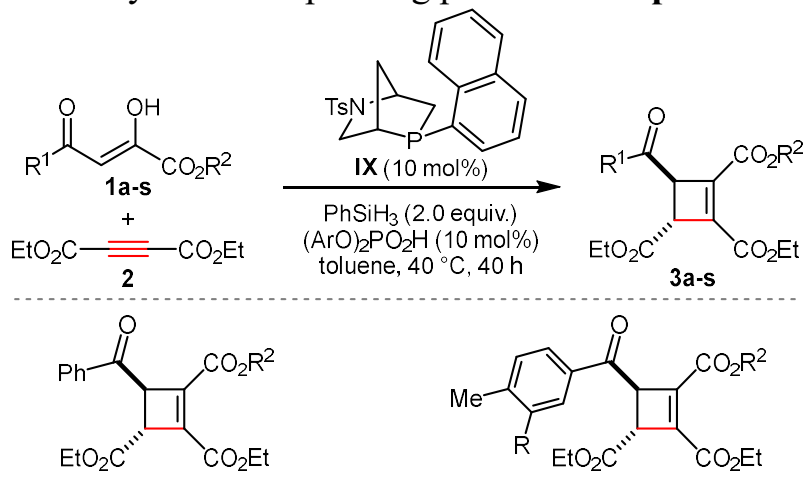

3a, $R^{2}=E t, 75 \%, 85 \% e^{[8]}$ 3 b, $R^{2}=\mathrm{Me}, 90 \%, 87 \% \mathrm{ee}^{[8]}$ 3c, $\mathrm{R}^{2}=n \mathrm{Bu}, 80 \%, 81 \%$ ee

3d, $\mathrm{R}=\mathrm{H}, \mathrm{R}^{2}=\mathrm{Et}, 63 \%, 89 \%$ ee 3e, $R=M e, R^{2}=E t, 56 \%, 83 \%$ ee

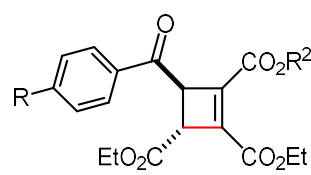

3f, $\mathrm{R}=\mathrm{H}, \mathrm{R}^{2}=n \mathrm{Bu}, 98 \%, 87 \%$ ee

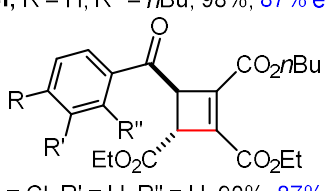

3g, $\mathrm{R}=\mathrm{OBn}, \mathrm{R}^{2}=n \mathrm{Bu}, 66 \%, 86 \%$ ee $3 \mathrm{j}, \mathrm{R}=\mathrm{Cl}, \mathrm{R}^{\prime}=\mathrm{H}, \mathrm{R}^{\prime \prime}=\mathrm{H}, 90 \%, 87 \%$ ee 3h, $R=C l, R^{2}=$ Et. $80 \%, 86 \%$ ee $\quad 3 \mathbf{k}, R=C l, R^{\prime}=C l, R^{\prime \prime}=H, 71 \%, 86 \%$ ee

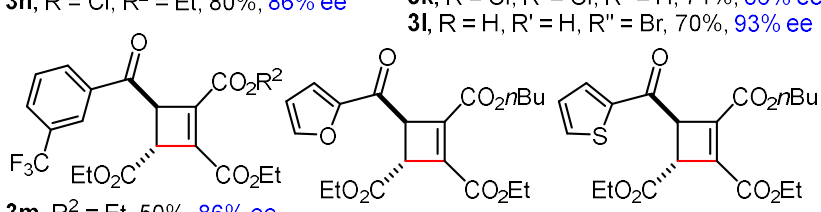

$3 \mathrm{~m}, \mathrm{R}^{2}=\mathrm{Et}, 50 \%, 86 \%$ ee 3n, $\mathrm{R}^{2}=n \mathrm{Bu}, 75 \%, 94 \%$ ee

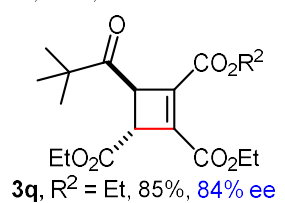

$3 \mathbf{r}, \mathrm{R}^{2}=n \mathrm{Bu}, 68 \%, 84 \%$ ee

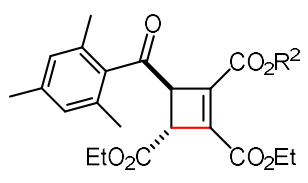

3s, $n r$

Scheme 3. Enantioselective phosphine-catalyzed synthesis of cyclobut-1-ene-1,2,3-tricarboxylates. 
Finally, alkyl 5,5-dimethyl-2,4-dioxohexanoate substrates 1q-r properly reacted to give products $3 \mathbf{3 q}-\mathbf{r}$ in $68-85 \%$ yields and $84 \%$ ee. The major diastereoisomer of all the products depicted in Scheme 3 was assigned to the trans-isomer, notably thanks to the two cyclobutanic proton $J_{\mathrm{H}-\mathrm{H}}$ couplings in ${ }^{1} \mathrm{H}$ NMR $(\delta \approx 3.85$ and $4.75 \mathrm{ppm}$, doublet, $J \approx 2.0 \mathrm{~Hz}$ ). As a general trend, such compounds show typical $J$ constants of 3.0-5.0 Hz for the cis-isomer and 0.5-2.0 $\mathrm{Hz}$ for the trans-isomer. ${ }^{[7]}$ Highly hindered substrates such as 1s, substituted with a 1,3,5-trimethylphenyl substituent did not react, highlighting one of the limitations of this reaction. No conversion was observed in this case, even by increased heating of the reaction mixture.

We then extended the reaction scope to the synthesis of fluorinated cyclobutenes (Scheme 4). The potential formation of new perfluoroethyl- and difluoropropylsubstituted products is of great interest given the large number of applications of fluorinated molecules as active pharmaceutical ingredients (APIs) and agrochemicals. ${ }^{[13]}$ The use of a stoichiometric amount of triphenylphosphine gave the racemic products 5a-b in $62-95 \%$ yields. After some optimization and screening of chiral phosphines I-IX, we were able to obtain at best the fluorinated compound $\mathbf{5 a}$ and $\mathbf{5 b}$ with good isolated yields and moderate enantioselectivities (71-72\% ee).

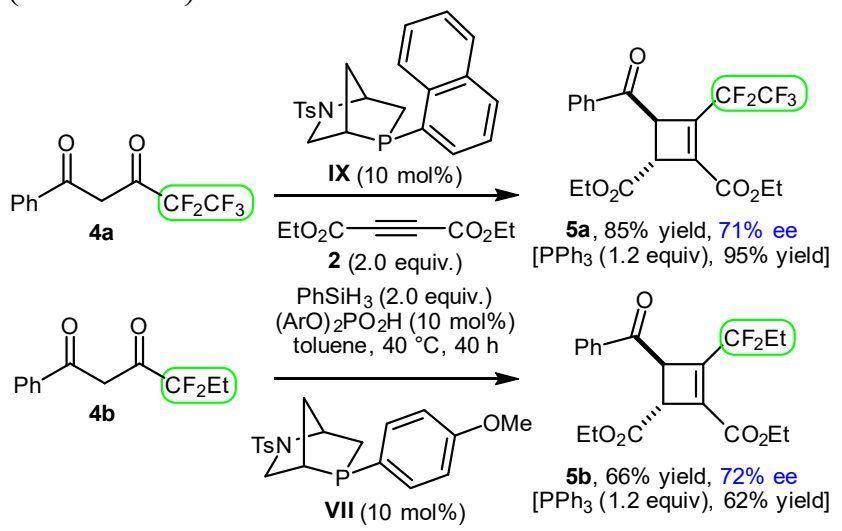

Scheme 4. Synthesis of chiral perfluoroethyl- and 1,1difluoropropyl-cyclobutene derivatives.

To further increase the substrate scope of this study, we envisaged its application in the synthesis of fluorinated spiro(cyclobutane)indenones 7 (Scheme 5). Whether with the use of 1.2 equivalents of $\mathrm{PPh}_{3}$ (Condition A) or $10 \mathrm{~mol} \%$ of chiral phosphine IX (Condition $B$ ), yields were lower than in the case of the synthesis of cyclobutenes $\mathbf{3}$ or $\mathbf{5}$. This lesser reactivity could be explained by the highly-strained spirocyclic ring system of 7a-g and the inherent difficulty in the formation of such scaffolds. Fortunately, the enantiomeric excesses reached $86-90 \%$ for compounds 7a-c. However, it was not possible to isolate enantioenriched products $\mathbf{7 d - f}$, even by using harsher reaction conditions or changing the chiral organocatalyst. Some modest preliminary results were obtained in the synthesis of $\mathrm{CF}_{3}$-substituted spiro[3.5]non-1-en-5-one $7 \mathbf{g}$ (up to $42 \%$ ee).

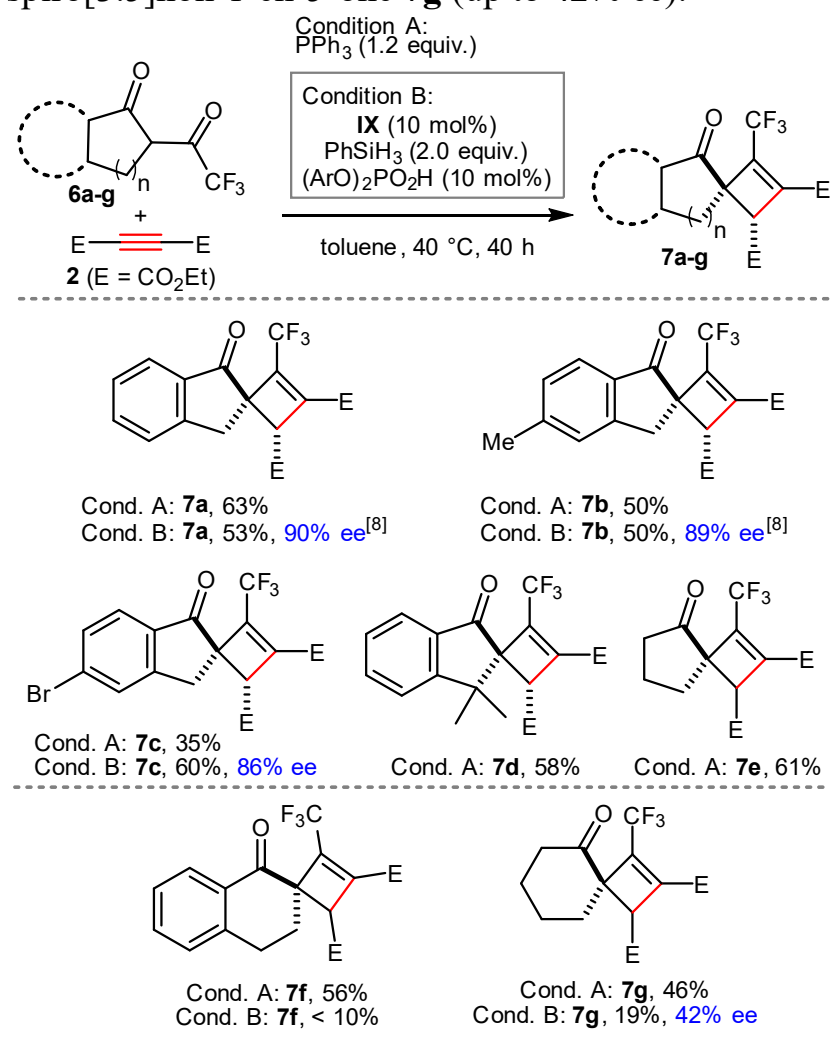

Scheme 5. Synthesis of spirocyclic-cyclobutene compounds.

To ascertain the relative configuration of the spirocyclic compounds, 7c was derivatized in the presence of (3,4-dinitrophenyl)hydrazine (Scheme 6). $\mathrm{X}$-ray diffraction studies of compound $\mathbf{8}$ allowed us to assign for the first time the trans-configuration of compound $7 \mathrm{c}$.
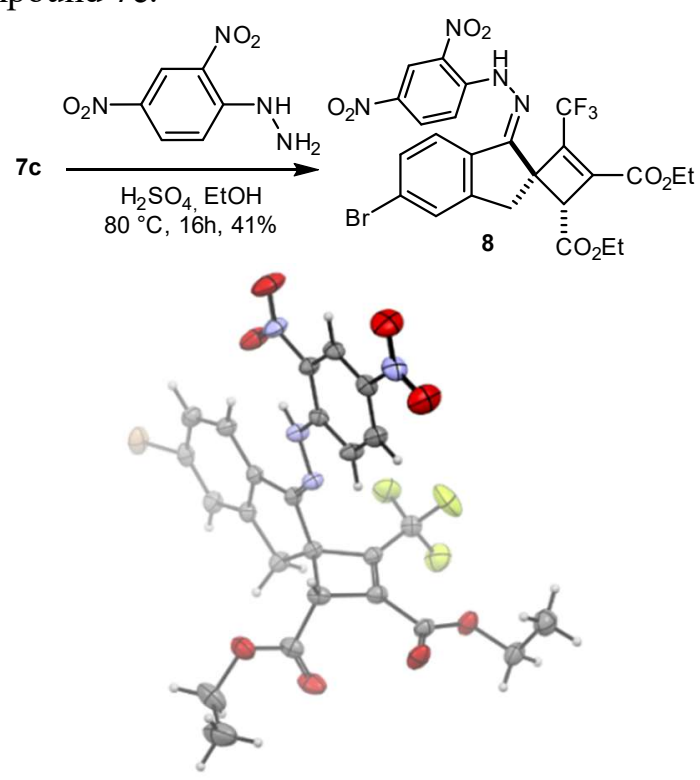

Scheme 6. Derivatization of $7 \mathbf{c}$ and ORTEP view of $\mathbf{8}$. Ellipsoids are drawn at the $50 \%$ probability level. 
We then wanted to explore the reactivity of 1-oxo2,3-dihydro- $1 H$-indene-2-carboxylate substrates 9a-b (Scheme 7). Surprisingly, the NMR analysis of 10a-b revealed the presence of two esters and two ketones, instead of the expected three esters and one ketone. The structural assignment of this new spirocyclic backbone was then confirmed by X-ray diffraction study on a single crystal of $\mathbf{1 0 b}$. With the use of stoichiometric amount of $\mathrm{PPh}_{3}$ (Condition A), spiro(cyclopentane)indenones $10 \mathrm{a}$ and $\mathbf{1 0 b}$ were isolated in 57-68\% yield. In the presence of $10 \mathrm{~mol} \%$ of HypPhos phosphine VII, phenylsilane (2.0 equivalents) and a catalytic amount of bis(4nitrophenyl)phosphate (Condition $B$ ), products 10a,b were synthesized in decent yields, with $72 \%$ ee. This methodology could be extended to the isolation of spiro[4.4]non-2-ene-1,6-dione 10c. For this substrate, the right balance between reactivity and selectivity was difficult to achieve $\left(27 \%\right.$ yield $/ 66 \%$ ee at $40{ }^{\circ} \mathrm{C}$ or $61 \%$ yield $/ 62 \%$ ee at $60{ }^{\circ} \mathrm{C}$ ). Finally, when a less constrained 6-membered ring was used, such as the ethyl 2-oxo-2-(2-oxocyclohexyl)acetate substrate, cyclobutene triester 11 was isolated. ${ }^{[7 c]}$ Unfortunately, none of the tested chiral phosphines gave satisfactory results with this substrate.
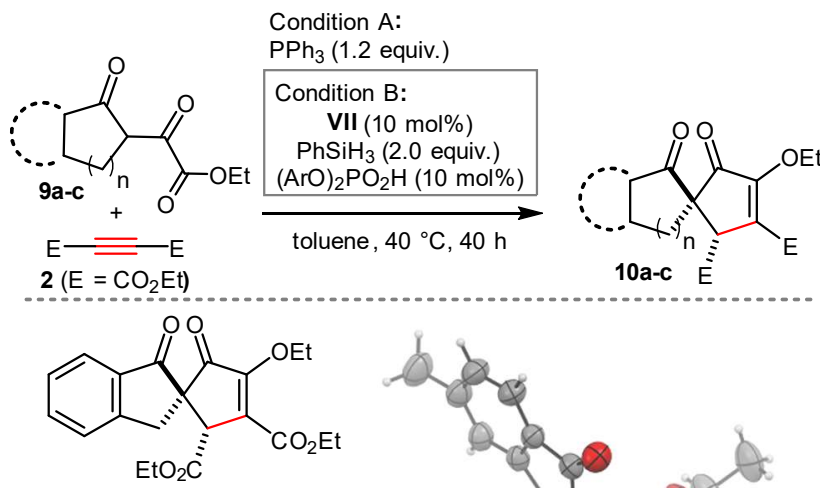

Cond. A: $10 \mathrm{a}, 68 \%$

Cond. B: $10 a, 68 \%, 72 \%$ ee

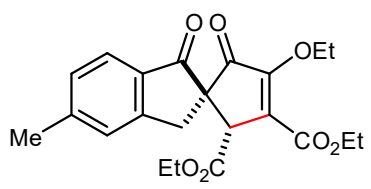

Cond. A: $10 \mathrm{~b}, 57 \%$

Cond. B: 10 b, $57 \%, 72 \%$ ee

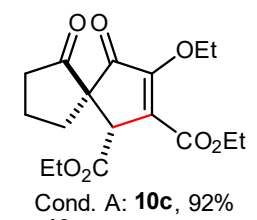

Cond. B: $10 \mathrm{c}, 27 \%, 66 \%$ ee $\left(40{ }^{\circ} \mathrm{C}\right)$

Cond. B: $10 \mathrm{c}, 61 \%, 62 \%$ ee $\left(60^{\circ} \mathrm{C}\right)$

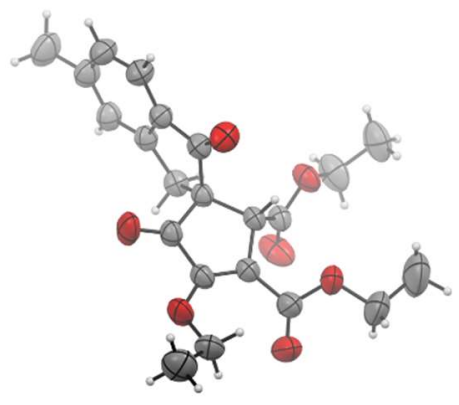

10b, CCDC 2077651

Scheme 7. Synthesis of new spirocyclic compounds 10a-c and 5-oxospiro[3.5]non-1-ene derivative 11.

The preferential formation of either cyclopentenone- or cyclobutene-fused spirocycles may be tentatively explained by mechanistic considerations (Scheme 8). The tandem reaction starts with the addition of the phosphine to DAAD substrate, to form the zwitterionic species (I). This intermediate subsequently deprotonates the substrates $6(\mathrm{EWG}=$ $\left.\mathrm{CF}_{3}\right)$ or 9 (EWG $\left.=\mathrm{CO}_{2} \mathrm{Et}\right)$, to give the vinylphosphonium salt (II). Addition of the enolate (III) to (II) generates in situ a phosphorus ylide (IV) or (V), which undergoes an intramolecular Wittig olefination to form the final spiro-butenes 7a-g or the spiro-cyclopentenones 10a-c and phosphine oxide. The reduction of phosphine oxide with phenylsilane closes the catalytic cycle. If the formation of the $\mathrm{CF}_{3}$ cyclobutene product 7 was expected, with the intermediate $(\mathbf{V})$ two Wittig reaction are possible, with the two carbonyl functions. In the case of synthesis of extremely strained spirocyclic compounds, the formation of compound $\mathbf{1 0}$ is favoured. As soon as the cycle strain is decreased, as in the case of the cyclohexanone product 11, the expected fourmembered ring was found again.

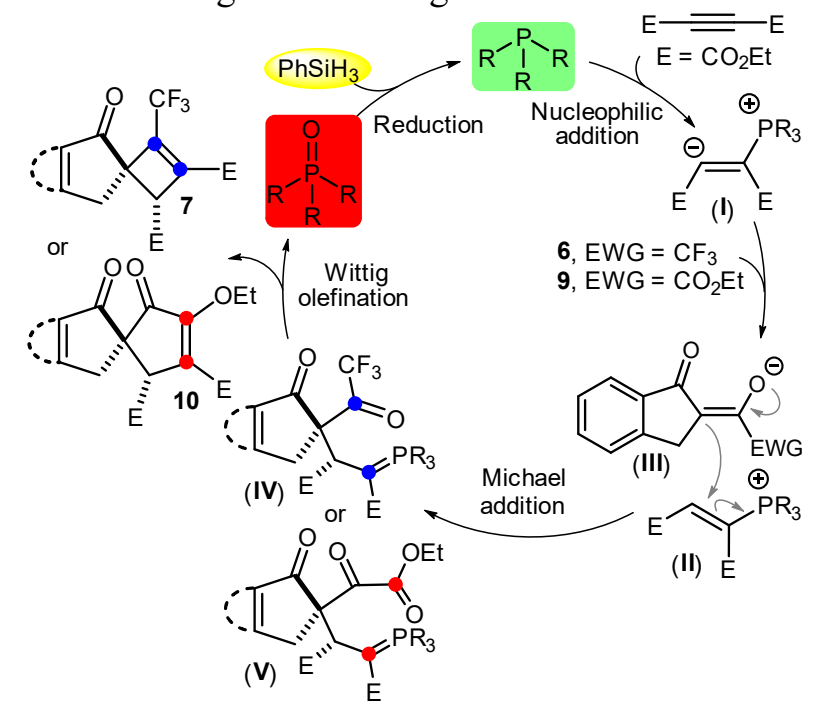

Scheme 8. Mechanistic proposal for the formation of compounds $7 / \mathbf{1 1}$ and $\mathbf{1 0}$.

In conclusion, we have synthesized benzoylcyclobutene triester derivatives via a $\mathrm{P}(\mathrm{III}) / \mathrm{P}(\mathrm{V})$ redox catalysis strategy. Products were isolated in good yields and enantioselectivities (18 examples, up to $94 \%$ ee). The synthesis of chiral perfluoroethyl- and 1,1-difluoropropyl-cyclobutenes was also developed. Extension of this methodology to spirocyclic compounds gave us the opportunity to discover significant divergence in reactivity between $\alpha$-substituted trifluoroacetyl- and ketoester-indenone substrates. Six spirocyclic compounds were isolated in moderate yields and good enantioselectivities (70$90 \%$ ee). Further studies on the development of new catalytic and asymmetric tandem reactions via redox catalysis are ongoing.

\section{Experimental Section}

The crystallographic data of $\mathbf{8}$ (CCDC 1983080) and 10b (CCDC 2077651) can be obtained free of charge from the Cambridge Crystallographic Data Centre via www.ccdc.cam.ac.uk/data_request/cif. Ellipsoids are drawn 
at the $50 \%$ probability level and $\mathrm{H}$ atoms are shown as spheres of arbitrary radius.

General procedure for the synthesis of substrates 1a-s. Diethyl oxalate $(5.5 \mathrm{mmol}, 1.1$ equiv.) was added to a suspension of sodium hydride $(7.5 \mathrm{mmol}, 1.5$ equiv. $)$ in distilled THF $(5 \mathrm{~mL})$ at $0{ }^{\circ} \mathrm{C}$. After 15 minutes, a solution of aryl methyl ketones (5.0 mmol, 1.0 equiv.) in distilled THF $(5 \mathrm{~mL})$ was then added dropwise for 5 minutes at the same temperature. The reaction was then stirred at $70{ }^{\circ} \mathrm{C}$ for 2 hours before to be quenched by addition of a solution of $\mathrm{HCl}(1 \mathrm{M})$ and extracted twice with EtOAc. The combined organic layers were washed with water, dried over $\mathrm{MgSO}_{4}$ and concentrated in vacuo. The crude mixture was then purified by automatic flash chromatography using silica gel pre-packed column and EtOAc/heptane as eluent (40-60\% EtOAc/heptane).

General procedures for the synthesis of products 3a-s and 7a-g. Synthesis of racemic products: Substrates 1 a-s or 6a-g $(0.075 \mathrm{mmol}, 1.0$ equiv. $)$ and triphenylphosphine $(0.09$ mmol, 1.2 equiv.) in anhydrous toluene $(0.75 \mathrm{~mL})$ were placed under argon into a Schlenk tube. Then diethyl but-2ynedioate 2 ( $0.15 \mathrm{mmol}, 2.0$ equiv.) was added and the solution was heated at $40{ }^{\circ} \mathrm{C}$ for $40 \mathrm{~h}$. The crude mixture was concentrated in vacuo before to be purified by column chromatography on silica gel (10-20\% heptane/EtOAc).

Synthesis of enantioenriched products: Substrates 1a-s or 6a-g $(0.075$ mmol, 1.0 equiv.), $(1 S, 4 S, 5 R)-5$-(naphthalen-1yl)-2-tosyl-2-aza-5-phosphabicyclo[2.2.1] heptane IX $(0.0075 \mathrm{mmol}, 10 \mathrm{~mol} \%)$ and bis(4-nitrophenyl) phosphate $(0.0075 \mathrm{mmol}, 10 \mathrm{~mol} \%)$ were placed under argon into a Schlenk tube and diluted with anhydrous toluene $(0.75 \mathrm{~mL})$. Diethyl but-2-ynedioate $2(0.15 \mathrm{mmol}, 2.0$ equiv) and phenylsilane ( $0.15 \mathrm{mmol}, 2.0$ equiv.) were then added using microsyringes. The solution was heated at $40{ }^{\circ} \mathrm{C}$ for $40 \mathrm{~h}$. After which it was concentrated in vacuo, the crude mixture was purified by column chromatography on silica gel (10$20 \%$ heptane/EtOAc).

\section{Acknowledgements}

The authors acknowledge the support of CHARMMMAT Labex (ANR-11-LABX-0039) and the Centre National de la Recherche Scientifique (CNRS). C.L. thanks MESRI (Paris-Saclay University) for a Ph.D. fellowship. Acknowledgement is made to the ACS GCI Pharmaceutical Roundtable Research Grant for partial support of this research (https://www.acsgcipr.org/).

\section{References}

[1] a) V. M. Dembitsky, J. Nat. Med. 2008, 62, 1-33; b) V. M. Dembitsky, Phytomedicine 2014, 21, 1559-1581; c) M. Wang, P. Lu, Org. Chem. Front. 2018, 5, 254-259; d) J. Li, K. Gao, M. Bian, H. Ding, Org. Chem. Front. 2020, 7, 136-154; e) D. Dorian, F. Reiners, Chem. Rec. 2021, 21, 1-18; f) M. R. Bauer, P. Di Fruscia, S. C. C. Lucas, I. N. Michaelides, J. E. Nelson, R. I. Storer, B. C. Whitehurst, RSC Med. Chem. 2021,12, 448-471.

[2] a) J. C. Namyslo, D. E. Kaufmann, Chem. Rev. 2003, 103, 1485-1538; b) T. Seiser, T. Saget, D. N. Tran, N. Cramer, Angew. Chem. Int. Ed. 2011, 50, 7740-7752; c) D. J. Mack, J. T. Njardarson, ACS Catalysis 2013, 3, 272-286; d) A. Misale, S. Niyomchon, N. Maulide, Acc. Chem. Res. 2016, 49, 2444-2458; e) G. Fumagalli, S. Stanton, J. F. Bower, Chem. Rev. 2017, 117, 9404-9432.
[3] a) F. Secci, A. Frongia, P. P. Piras, Molecules 2013, 18, 15541-15572; b) Y. Xu, M. L. Conner, M. K. Brown, Angew. Chem. Int. Ed. 2015, 54, 11918-11928; c) S. Poplata, A. Tröster, Y.-Q. Zou, T. Bach, Chem. Rev. 2016, 116, 9748-9815; d) K.-G. Wen, Y.-Y. Peng, X.-P. Zeng, Org. Chem. Front. 2020, 7, 2576-2597.

[4] a) K. Narasaka, Y. Hayashi, H. Shimadzu, S. Niihata, J. Am. Chem. Soc. 1992, 114, 8869-8885; b) H. Ito, M. Hasegawa, Y. Takenaka, T. Kobayashi, K. Iguchi, J. Am. Chem. Soc. 2004, 126, 4520-4521; c) C. Schotes, A. Mezzetti, Angew. Chem. Int. Ed. 2011, 50, 3072-3074; d) K. Enomoto, H. Oyama, M. Nakada, Chem. Eur. J. 2015, 21, 2798-2802; e) D. L. Smith, S. R. Chidipudi, W. R. Goundry, H. W. Lam, Org. Lett. 2012, 14, 49344937; f) K. Ishihara, M. Fushimi, J. Am. Chem. Soc. 2008, 130, 7532-7533; g) T. Kang, S. Ge, L. Lin, Y. Lu, X. Liu, X. Feng, Angew. Chem. Int. Ed. 2016, 55, 55415544; h) R. Kumar, E. Tamai, A. Ohnishi, A. Nishimura, Y. Hoshimoto, M. Ohashi, S. Ogoshi, Synthesis 2016, 48, 2789-2794; i) C. García-Morales, B. Ranieri, I. Escofet, L. López-Suarez, C. Obradors, A. I. Konovalov, A. M. Echavarren, J. Am. Chem. Soc. 2017, 139, 13628-13631; j) M. M. Parsutkar, V. V. Pagar, T. V. RajanBabu, J. Am. Chem. Soc. 2019, 141, 15367-15377. For [2+2] cycloaddition with strained bicyclic alkenes, see : k) T. Shibata, K. Takami, A. Kawachi, Org. Lett. 2006, 8, 1343-1345; 1) B.-M. Fan, X.-J. Li, F.-Z. Peng, H.-B. Zhang, A. S. C. Chan, Z.-H. Shao, Org. Lett. 2010, 12, 304-306; m) D. Kossler, N. Cramer, Chem. Sci. 2017, 8, 1862-1866; n) H. Qin, J. Chen, K. Li, Z. He, Y. Zhou, B. Fan, Chem. Asian J. 2018, 13, 2431-2434.

[5] a) C. Zhong, Y. Huang, H. Zhang, Q. Zhou, Y. Liu, P. Lu, Angew. Chem. Int. Ed. 2020, 59, 2750-2754; b) Z. Jiao, Q. Shi, J. S. Zhou, Angew. Chem. Int. Ed. 2017, 56 , 14567-14571. Other relevant work: c) M. Luparia, M. T. Oliveira, D. Audisio, F. Frébault, N. Maulide, Angew. Chem. Int. Ed., 2011, 50, 12631-12635; d) F.-G. Zhang, I. Marek, J. Am. Chem. Soc. 2017, 139, 8364-8370.

[6] a) M. M. Maturi, T. Bach, Angew. Chem. Int. Ed. 2014, 53, 7661-7664; b) K.-G. Wen, C. Liu, D.-H. Wei, Y.-F. Niu, Y.-Y. Peng, X.-P. Zeng, Org. Lett. 2021, 23, 1118 1122.

[7] a) I. Yavari, A. R. Samzadeh-Kermani, Tetrahedron Lett. 1998, 39, 6343-6344; b) I. Yavari, S. Asghari, Tetrahedron 1999, 55, 11853-11858; c) I. Yavari, M. Bayat, Tetrahedron 2003, 59, 2001-2005; d) M. H. Mosslemin, I. Yavari, M. Anary-Abbasinejad, M. R. Nateghi, Synthesis 2004, 1029-1032.

[8] C. Lorton, T. Castanheiro, A. Voituriez, J. Am. Chem. Soc. 2019, 141, 10142-10147.

[9] General reviews: a) A. Voituriez, N. Saleh, Tetrahedron Lett. 2016, 57, 4443-4451; b) H. C. Guo, Y. C. Fan, Z. H. Sun, Y. Wu, O. Kwon, Chem. Rev. 2018, 118, 1004910293; c) R. H. Beddoe, H. F. Sneddon, R. M. Denton, Org. Biomol. Chem. 2018, 16, 7774-7781; d) J. M. Lipshultz, G. Li, A. T. Radosevich, J. Am. Chem. Soc. 2021, 143, 1699-1721. Representative publications in the field, including our work: e) C. J. O'Brien, J. L. Tellez, Z. S. Nixon, L. J. Kang, A. L. Carter, S. R. 
Kunkel, K. C. Przeworski, G. A. Chass, Angew. Chem. Int. Ed. 2009, 48, 6836-6839; f) H. A. van Kalkeren, S. H. A. M. Leenders, C. R. A. Hommersom, F. P. J. T. Rutjes, F. L. van Delft, Chem. Eur. J. 2011, 17, 1129011295; g) H. A. van Kalkeren, J. J. Bruins, F. P. J. T. Rutjes, F. L. van Delft, Adv. Synth. Catal. 2012, 354, 1417-1421; h) T. Werner, M. Hoffmann, S. Deshmukh, Eur. J. Org. Chem. 2014, 6630-6633; i) K. Fourmy, A. Voituriez, Org. Lett. 2015, 17, 1537-1540; j) M.-L. Schirmer, S. Adomeit, T. Werner, Org. Lett. 2015, 17, 3078-3081; k) N. Saleh, A. Voituriez, J. Org. Chem. 2016, 81, 4371-4377; 1) N. Saleh, F. Blanchard, A. Voituriez, Adv. Synth. Catal. 2017, 359, 2304-2315; m) T. V. Nykaza, T. S. Harrison, A. Ghosh, R. A. Putnik, A. T. Radosevich, J. Am. Chem. Soc. 2017, 139, 68396842 ; n) K. Zhang, L. C. Cai, Z. Y. Yang, K. N. Houk, O. Kwon, Chem. Sci. 2018, 9, 1867-1872; o) X. Han, N. Saleh, P. Retailleau, A. Voituriez, Org. Lett. 2018, 20, 4584-4588; p) L. Cai, K. Zhang, S. Chen, R. J. Lepage, K. N. Houk, E. H. Krenske, O. Kwon, J. Am. Chem. Soc. 2019, 141, 9537-9542; q) L. Longwitz, T. Werner, Angew. Chem. Int. Ed. 2020, 59, 2760-2763; r) G. Li, T. V. Nykaza, J. C. Cooper, A. Ramirez, M. R. Luzung, A. T. Radosevich, J. Am. Chem. Soc. 2020, 142, 6786-6799.
[10] For reviews on spiro compounds, see: a) E. M. Carreira, T. C. Fessard, Chem. Rev. 2014, 114, 8257-8322; b) A. S. Ding, M. Meazza, H. Guo, J. W. Yang, Rios, R., Chem. Soc. Rev. 2018, 47, 5946-5996.

[11] a) C. E. Henry, Q. H. Xu, Y. C. Fan, T. J. Martin, L. Belding, T. Dudding, O. Kwon, J. Am. Chem. Soc. 2014, $136,11890-11893$; b) It is important to note that $P$ stereogenic phosphines I-IX are configurationally stable in the reaction conditions and that corresponding phosphine oxides are reduced with retention of stereochemistry.

[12] D. Herault, N. Duc Hanh, D. Nuel, G. Buono, Chem. Soc. Rev. 2015, 44, 2508-2528.

[13] a) J. Wang, M. Sánchez-Roselló, J. L. Aceña, C. del Pozo, A. E. Sorochinsky, S. Fustero, V. A. Soloshonok, H. Liu, Chem. Rev. 2014, 114, 2432-2506; b) Y. Zhou, J. Wang, Z. Gu, S. Wang, W. Zhu, J. L. Aceña, V. A. Soloshonok, K. Izawa, H. Liu, Chem. Rev. 2016, 116, 422-518 